\title{
Constructing Multidimensional and Integrated Experimental Teaching System of Economics and Management
}

\author{
Niu Li \\ Key Laboratory of Ministry of Education for Data \\ Engineering and Knowledge Engineering \\ Renmin University of China \\ Beijing, China \\ rucniuli@gmail.com
}

\author{
Han Xiaoting \\ School of Economics and Management \\ Beihang University \\ Beijing, China \\ hanxiaoting@buaa.edu.cn \\ ((corresponding author)
}

\begin{abstract}
Aimed at cultivating interdisciplinary talents of economics and management with high quality, this paper proposes a multidimensional and integrated experimental teaching system, and further innovates diversified experimental teaching methods and cross-border experimental teaching organization. The proposed experimental teaching system has been applied in School of Economics and Management of Beihang University, and successfully cultivates students' executive, innovative and comprehensive ability, which can be used as reference for experiment teaching reform of other business schools.
\end{abstract}

Keywords-Experiment Teaching; Economics Management; Multidimensional and Integrated System

\section{INTRODUCTION}

Experiment teaching is an effective teaching activity to realize the construction of knowledge, enhance ability, and improve the cultivation quality, which plays an important part in high education. Due to the particularity of the economics and management experiments, the experiment teaching is of great importance to the cultivating of economics and management talents. However, economics and management experimental teaching in China starts late, which is still at the exploration stage and exists such problems as lack of systemic. Therefore, it is of great theory value for supplementing and perfecting Chinese higher education theory system to systematically study the economics and management experimental teaching. In addition, it is of great practical significance to for training college talents of economics and management to meet the needs of social and academic requirements with high quality.

\section{MULTI-DIMENSIONAL EXPERIMENT TEACHING SYSTEM IN ECONOMICS AND MANAGEMENT}

According to students' cognitive regularity and the experimental teaching goal, teaching course content system of economics and management experiment is as shown in figure 1, the characteristics of the system are "integration, multidimensional."

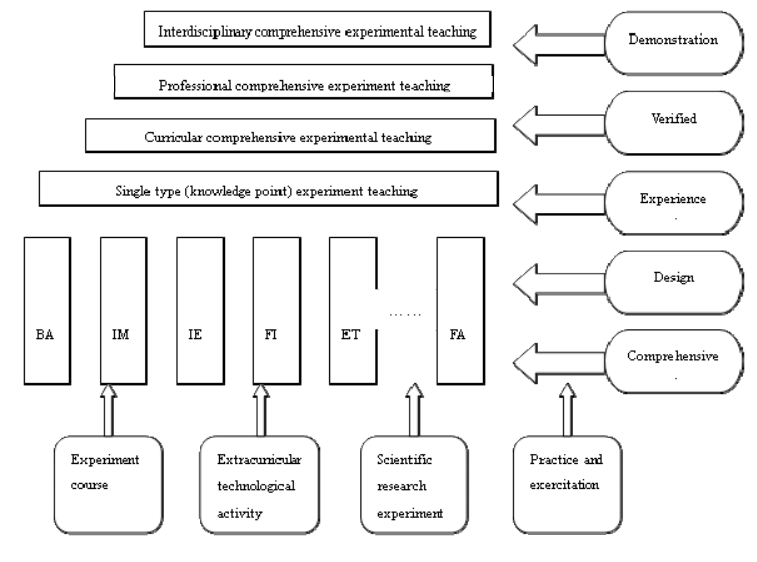

Figure 1. Course content of experiment teaching system in economics and management

\section{A. Integrated Experiment Teaching System in Economics and Management}

(1) Integration of Course Content in Experiment Teaching System

Integrated experiment contents of economics and management system and puts emphasis on the whole and mutual connection. It requires overall planning, reasonable arrangement of the experimental teaching content and experimental project order, so as to ensure consistency between experimental curriculum and experimental content.

(2) Integration of Experiment Teaching with Theory Teaching

The system of economics and management experiment course should combine experimental teaching with theory teaching, forming the integral curriculum system. It can ensure students to do the experiment with a good master of relevant theoretical knowledge, and at the same time, to supplement students' knowledge system through the experimental teaching.

(3) Integration of Teaching and Research

Economics and management experimental teaching should follow the academic front, and the teachers must use innovation knowledge and innovation achievements by 
scientific study to feedback and improve the quality of experiment teaching, and to promote the scientific research.

\section{B. Multi-Dimensional Contents of Experiment Teaching System in Economics and Management}

\section{(1) Types and Hierarchy}

To study and integrate the present economics and management experiment research in universities, this paper divides economics and management experiment into five types, namely the demonstration type, and validation type, experience type, and design research type, as well as integration type, according to the difference between economics and management experiment and science experiment.

At the same time, considering the students' learning needs in different grades and different periods with different aims, the experiment course system with a progressive level will be built according to the difficulty of experiment teaching, from a single type, integrated comprehensive type to a professional comprehensive type and cross-curriculum comprehensive type. Besides, according to the characteristics of each experiment, the system is categorized into the twodimensional experimental system is shown in figure 2 .

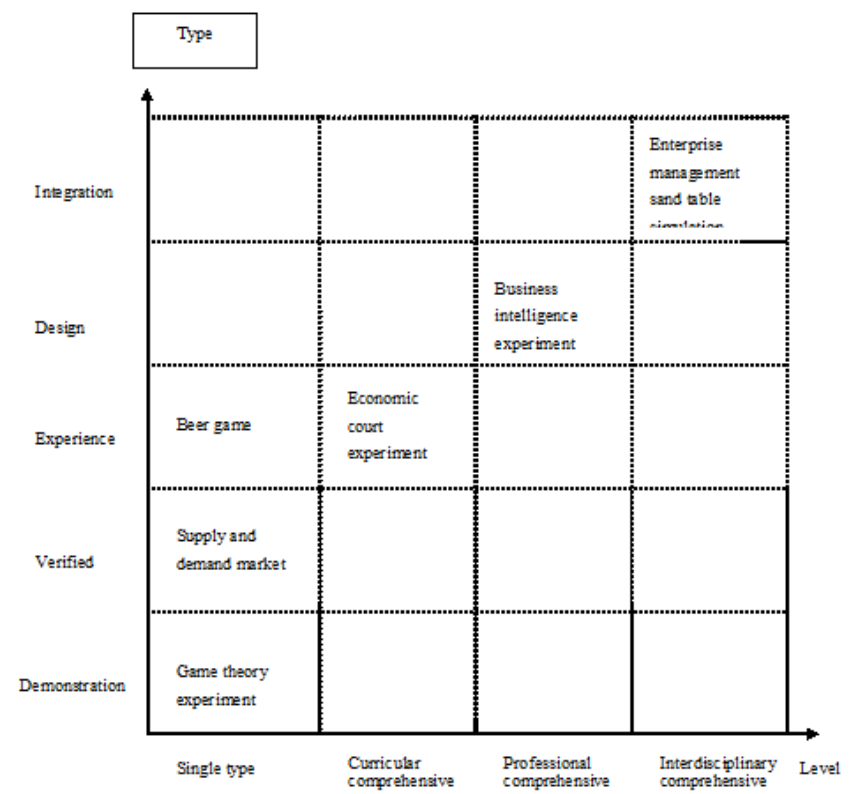

Figure 2. types and hierarchy of economics and management experiment

(2) Experiment Application

In economics and management disciplines, the experiment not only is a must in the usual curriculums, but also supports extracurricular science and technology experiment, academic research projects, and the students' practice and internship. It requires designing the experiment related to the experimental curriculum outside the regular classroom instructions, to guide the students' extracurricular technology and scientific research, as well as the social practice and production internships.

(3) Experiment Modules

The system of economic managing and teaching experiment should break the tradition to distinguish experiment in terms of disciplines, specialties and courses.
It should also fully analyze the characteristics of economics and management specialties and the association between the courses, and then sort out the relevant contents about the teaching in the experiment courses with the use of information technology or others. The system, covered by economy, finance, management and experiment courses in the system of economic managing and teaching experiment, can be transversely divided into several modules. The modules mutually differ from each other with their research objects, research contents and methods. And they also both mutually relate, which belong to economic and financial specialty together.

\section{DIVERSIFIED EXPERIMENTAL TEACHING METHODOLOGY FOR ECONOMICS AND MANAGEMENT}

\section{A. Idea of Experiment Teaching}

Under the guidance of current education idea and current pedagogical methodology, teachers should follow constructive ideas. And one would alternate from teaching knowledge to those including design of teaching content, creation of learning environment, configuration of learning resources, guidance of the direction of learning, coaching of learning difficult, monitoring of the learning process, and assessment of learning outcomes. During the process of experiment management teaching, the teacher plays a role of organizer, guider and helper. Teachers can make full use of learning factors such as situations, cooperation, conversations and so on. By normalizing the learning styles of students and actively motivating students' initiatives and creativity, teachers can help students think effectively, improve ability and finally grasp the knowledge. Students are no more the passive acceptors of knowledge. Instead, they can explore the knowledge not only from classes and teachers, but also from libraries, network and partners.

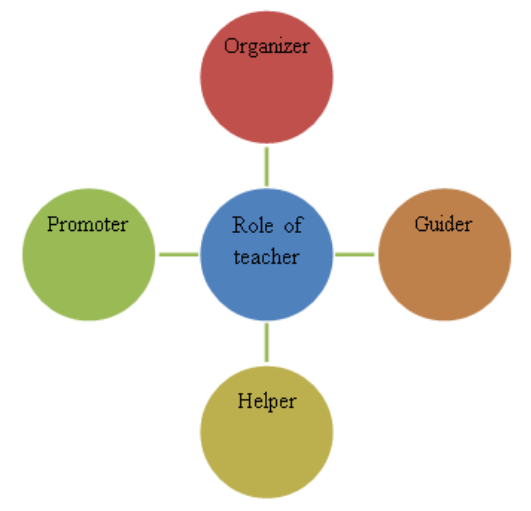

Figure 3. teacher's roles in economics and management experiment teaching

\section{B. Organization of Experiment Teaching}

There are five steps for the organization of experiment teaching. First, analyze knowledge system according to knowledge points to establish pedagogical goal. Second, summarize knowledge points and build up pedagogical environment. Third, organize students into groups by roles. Then, encourage student-centered cooperative study in the process of teaching. Finally, after the experiment and teaching, teachers will comment on the result, and the experts and students examine the experiment teaching. 


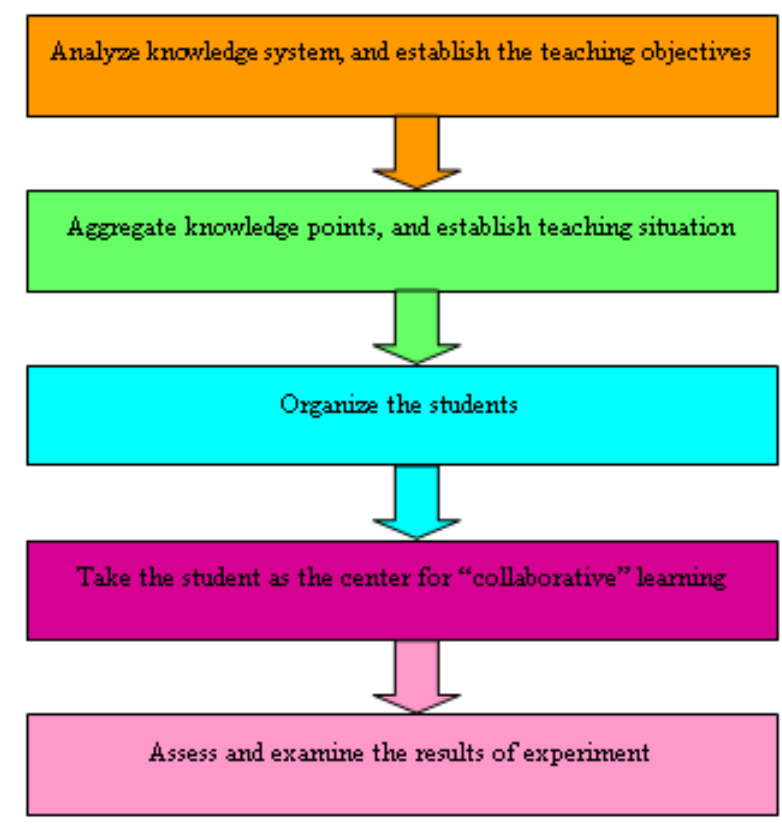

Figure 4. organization of experiment and pedagogical procedures

\section{Diversified Experiment and Pedagogical Methodology}

In order to adapt diversified teaching model of experiment teaching in economics and management, teaching modes of participatory and self-study by students should be fully applied in the economics and management experiment teaching. People can introduce a variety of advanced teaching methods, such as sand table exercise method, game theory, team learning, project-driven method, participatory teaching, self-learning, experiential learning, interactive teaching, online communication, and so on, to economics and management review method experimental teaching. And the impact on the effectiveness and efficiency of experimental teaching could be analyzed from experiments feedbacks, questionnaires and other forms.

\section{ORgANIZATION OF CROSS-BORDER EXPERIMENT TEACHING IN ECONOMICS AND MANAGEMENT}

\section{A. Organization of Experiment Teaching}

Economics and management experiment teaching should be coordinated by a special organization. The main responsibilities are as follows: study experiment teaching modes, design experimental teaching system, summarize the experimental teaching experiences, and organize experimental teaching training and promotion. Due to the complexity features of economics and management experiment teaching system, experimental teaching centers should adopt "combining centralization and decentralization" management. The centralized management is mainly in charge of the construction and management aspects of the experimental teaching center. It includes unified planning, unified construction, unified resource, unified technical support and unified management. The decentralized management is mainly reflected in the implementation of the experimental teaching. That is to design the experimental courses, arrange the experimental teaching plan and contents, and organize the experimental teachings, which should be answered by the respective disciplines or faculties.

\section{B. Experiment Teaching Organized by Teachers}

As the management issues are generally very complex, in economics and management experimental teaching, we should break the boundaries between disciplines and construct experimental teaching staff, including different faculties, experimental teaching center manager and technical support staff, external teachers, high grade or graduate teaching assistants, as shown in Figure 5. Meanwhile, for the multi-disciplinary comprehensive experiment, it should include staff from different teaching units and different professions.

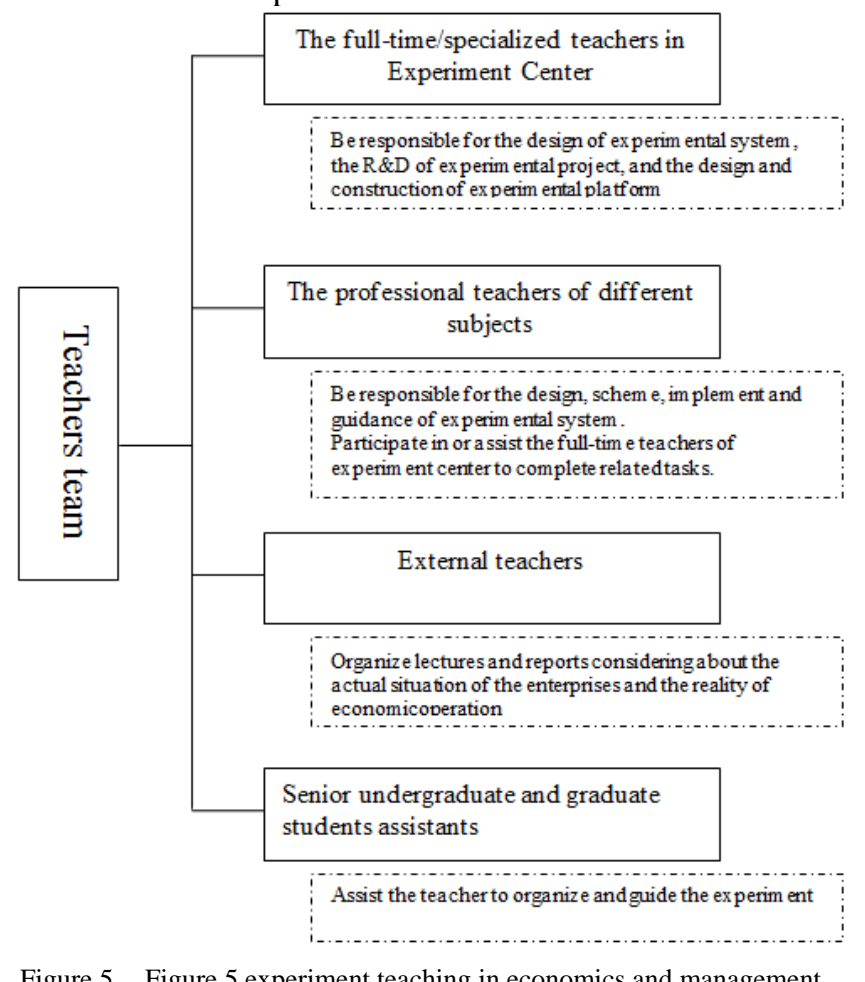

Figure 5. Figure 5 experiment teaching in economics and management organized by teachers

\section{Experiment Teaching Organized by Students}

To adapt to the professional and comprehensive characteristics of economic teaching management, the organization of economics and management experiment should be in a rich and diversifying form. Different student organizations should be applied in every type and level of the experimental teaching. It is in the form of disciplinaryspecific and multi-disciplinary organization.

\section{CONCLUSIONS}

With purposes of cultivating high-quality economics and management talents, this paper systemically proposed multi-dimensional experimental teaching contents of economics and management, and then innovates diversified experimental teaching methods and crossborder organizational forms in teaching. This proposed system emphasizes on the integration of multi-disciplines and cultivation of students' creativity and overall quality, which serves as an effective approach for the School of 
Economics and Management in Beihang University to cultivate qualified inter-disciplinary talents.

The experiment teaching system proposed above has been applied in the School of Economics and Management in Beihang University for 4 years, and helps formulate an experimental teaching mode in economics and management. As a result, this system integral develop students' academic knowledge, professional capability and innovation ability, comprehensively enhances teaching and learning quality as well as faculty's capability, creates a virtuous cycle in teaching and learning, and effectively promotes the disciplinary development of business.

\section{ACKNOWLEDGMENT}

This paper is supported by the Fundamental Research Funds for the Central Universities, and the Research Funds of Renmin University of China (Project Number: 14XNJ026; Project Name: Information Diffusion and Node Influence Analysis in Heterogeneous Social Networks).

\section{REFERENCES}

[1] Ellington H., Fowlie J., Gordon M. Using Games and Simulations in the Classroom: A Practical Guide for Teachers. Routledge, 2013

[2] Keys B., Wolfe J. 1990. “The Role of Management Games and Simulations in Education and Research," Journal of Management, 16(2): 307-336
[3] Han Xiaoting, Niu Li. Design a Five-in-one Experiment Teaching System of Economics and Management [A]. Proceedings of 2015 International Workshop on Social Science Progress [C]. Sanya, China, 2015.

[4] Han Xiaoting, Niu Li. Enterprise resources planning sand table training for engineering students [J]. Applied Mechanics and Materials, 2012, v 121-126: 825-829.

[5] Pasin F., Giroux H. 2011. "The Impact of a Simulation Game On Operations Management Education,” Computers \& Education, 57(1): 1240-1254

[6] Xiaoting Han, Li Niu. Constructing Virtual Business Environment Simulation Platform for Multi-Major of Economics and Management in Higher Education [A] Proceedings of 2013 International Conference on Cyber Science and Engineering [C]. Guangzhou, China, December 14-15, 2013.

[7] Hu J, Zhang M, Huang X. How To Setup a Continuous Experimental Teaching System: Case Study On The Tourism Management Program[J]. Higher Education Studies, 2014, 4(2): p70.

[8] Xiaoting $\mathrm{H}, \mathrm{Li}$ N. Design of a Five-in-one Experiment Teaching System of Economics and Management[C]//2015 International Conference on Social Science and Technology Education. Atlantis Press, 2015.

[9] Wang C, Ye Q. An Exploration on "Systematic Class" Teaching Reform for Economics and Management Majors in Universities[C]//2014 International Conference on Education Reform and Modern Management (ERMM-14). Atlantis Press, 2014.

[10] Karlan D, Valdivia M. Teaching entrepreneurship: Impact of business training on microfinance clients and institutions[ $\mathrm{J}]$. Review of Economics and Statistics, 2011, 93(2): 510-527. 